\title{
ISIDRO ALIAU: MAESTRO, INSPECTOR Y REFORMISTA EN LOS ORÍGENES DEL SISTEMA EDUCATIVO ARGENTINO
}

\author{
Isidro Aliau: teacher, inspector and reformist in the origins \\ of the Argentine educational system
}

\section{Mónica Baretta ${ }^{\circ}$}

Fecha de recepción: 02/10/2020 • Fecha de aceptación: 15/03/2021

Resumen. A mediados del siglo XIX, la progresiva consolidación de los Estados independientes en el espacio americano abrió nuevos debates relacionados con la necesidad de extender la educación escolarizada al conjunto de la población. Desde ese contexto, este artículo se propone abordar la figura de Isidro Aliau, un maestro catalán exiliado en Argentina que desempeñó entre 1876 y 1887 el cargo de Inspector General de Escuelas de la provincia de Santa Fe (República Argentina). A partir de allí, se presentarán algunas de sus contribuciones pedagógico-lingüísticas, escasamente discutidas tanto en el campo de la historia de la educación como en el plano de las políticas del lenguaje. El interés estará centrado en dos de sus principales aportes: la elaboración de un método de enseñanza simultánea de la lectura y la escritura para ser usado en escuelas primarias, y la presentación de un proyecto para reformar la ortografía del español, cuyo fundamento era simplificar la escritura como vía para facilitar el aprendizaje. Estas producciones serán interpretadas como intervenciones políticas en el plano del lenguaje, en la medida en que suponen un intento por afectar el reparto social de la palabra, en el marco de una voluntad alfabetizadora y democratizante de la educación.

Palabras clave: ortografía; alfabetización; educación; lectura; Argentina.

Abstract. In the middle of the 19th century, the progressive consolidation of the American independent states opened new debates related to the need to extend school-based education to the entire population. Within this framework,

\footnotetext{
a Centro de Estudios del Lenguaje en Sociedad (CELES) - Laboratorio de Investigación en Ciencias Humanas (LICH), Escuela de Humanidades, Universidad Nacional de San Martín. Campus Miguelete, Martín de Irigoyen 3100, (1650) San Martín (Bs. As.), República Argentina. monicabaretta@ gmail.com
} 
this article aims to address the figure of Isidro Aliau, a Catalan teacher exiled in Argentina who between 1876 and 1887 held the position of Inspector General of Schools in the province of Santa Fe (Argentine Republic). From there, some of his pedagogical-linguistic contributions will be presented, contributions that have received scarce attention either in the field of the history of education or in the field of language politics. The article focuses on two of his main contributions: the development of a simultaneous teaching method of reading and writing to be used in primary schools, and the presentation of a project to reform the orthography of Spanish language, whose foundation was to simplify writing as a way to facilitate learning. These contributions are interpreted as political interventions in the realm of language, insofar as they represent an attempt to affect the social distribution of the written word, within the framework of an endeavor to expand literacy and democratize education.

Keywords: orthography; literacy; education; reading; Argentina.

\section{INTRODUCCIÓN}

La segunda mitad del siglo XIX constituye un momento histórico particularmente fértil para el estudio de las intervenciones públicas en el plano del lenguaje, sobre todo en el caso argentino. La progresiva consolidación del sistema educativo, la ampliación de los públicos lectores, la expansión de la prensa y los procesos de institucionalización del Estado moderno son elementos propios de ese período, que han dado lugar a un amplio abanico de investigaciones que analizan el modo en que diversos actores han buscado representar y regular las prácticas letradas. En algunos casos, se analizó esa regulación en el plano del debate público, a partir de la proliferación de discursos normativos en relación con la lengua española en el Río de la Plata, ${ }^{1}$ otros han estudiado las intervenciones a través de la construcción de instrumentos lingüísticos, como pueden ser los diccionarios ${ }^{2} \mathrm{y}$, en otros casos, se ha prestado particular atención al modo en que esa voluntad agentiva se articuló con el campo pedagógico a través de legislaciones educativas que buscaron

\footnotetext{
1 Ángela Di Tullio, Políticas lingüísticas e inmigración. El caso argentino (Buenos Aires: Eudeba, 2010); Juan Antonio Ennis, Decir la lengua: Debates ideológico-lingüísticos en Argentina desde 1837 (Frankfurt am Main: Peter Lang, 2008).

2 Daniela Lauria, «Los diccionarios argentinos de "barbarismos": análisis glotopolítico de los publicados entre 1890 y 1903», Káñina, XLIII, 3 (2019): 39-66.
} 
regular las lenguas de enseñanza. ${ }^{3}$ Asimismo, algunos abordajes históricos han estudiado ampliamente las prácticas alfabetizadoras de ese período, aportando conocimiento acerca de los métodos y las prácticas que organizaron la enseñanza de la lectura y la escritura en el país. ${ }^{4}$

Este artículo pretende sumar nuevas aristas a esa discusión, a partir del estudio preliminar de la obra de Isidro Aliau, un maestro catalán exiliado en Argentina que desempeñó entre 1876 y 1887 el cargo de Inspector General de Escuelas de la provincia de Santa Fe. Entre otras contribuciones, Aliau produjo dos publicaciones orientadas a incidir de manera directa en las prácticas letradas: escribió un método de enseñanza simultánea de la lectura y la escritura para ser usado en escuelas primarias, y elaboró un proyecto para reformar la ortografía del español cuyo fundamento era simplificar la escritura como vía para facilitar el aprendizaje e igualar a los sujetos de la educación.

Las intervenciones sobre la escritura, ya sea a través de normativas explícitas como legislaciones o instrumentos lingüísticos (gramáticas, diccionarios, ortografías), o bien a través de discursos que versan sobre algún aspecto de la práctica, implican insoslayablemente una disputa por el poder. Es que, tal como observa Arnoux, la voluntad de actuar sobre la lengua se presenta vinculada con transformaciones económicas y sociales relevantes para una comunidad en un determinado momento: lo que se manifiesta muchas veces como un problema lingüístico es un efecto de desplazamiento de otro tipo de conflictos de orden político, económico o social. ${ }^{5}$ Así, la progresiva consolidación de los Estados independientes en el espacio americano abrió nuevos debates relacionados con la necesidad de extender la educación escolarizada al conjunto de la población. Ese contexto alentó una acelerada proliferación de prácticas,

\footnotetext{
3 Elvira Arnoux, «Las leyes de defensa de la lengua en la Argentina: propuestas y debates al finalizar los siglos XIX y XX», Letterature d'America, XXIV, 100 (2003): 23-50.

4 Mariana Di Stefano, El lector libertario. Prácticas e ideologías lectoras del anarquismo argentino (1898-1915) (Buenos Aires: Eudeba, 2013); Héctor Cucuzza y Pablo Pineau (eds.), Para una historia de la enseñanza de la lectura y escritura en Argentina. Del catecismo colonial a La Razón de Mi Vida (Buenos Aires: Miño y Dávila, 2018).

5 Elvira Arnoux, «Glotopolítica: delimitación del campo y discusiones actuales con particular referencia a Sudamérica», en Lengua y política en América Latina: Perspectivas actuales; Actas del II Coloquio Internacional de Estudios Latinoamericanos de Olomouc (Olomouc: Univerzita Palackého v Olomouci, 2014) s/p.; Elvira Arnoux, «Marcar la nación en la lengua: la reforma ortográfica chilena (1843-1844)», Revista de Estudios de Ciencias Sociales y Humanidades, 16 (2006): 41-54.
} 
normas y representaciones acerca de la lengua y del modo de enseñarla, inscriptas en determinados posicionamientos políticos más generales.

En este artículo, las intervenciones públicas de Isidro Aliau serán interpretadas como intervenciones políticas sobre el lenguaje, en la medida en que suponen un intento por afectar «el reparto social de la palabra ${ }^{6}$ en el marco de una voluntad alfabetizadora y democratizante de la educación. En primer lugar, se presentará brevemente la trayectoria biográfica de Aliau y las características del contexto en el cual se desempeñó como funcionario del gobierno de Santa Fe. Posteriormente, se presentará y examinará su Método razonado para enseñar a leer y escribir simultáneamente (1878) y, a continuación, se abordará su tratado Sobre la reforma de la ortografía actual (1882). Finalmente, se presentarán algunas observaciones orientadas a propiciar la discusión del personaje y su obra.

\section{RECORRIDO BIOGRÁFICO}

Isidro Aliau nació el 15 de mayo de 1829 en Tivenys, un pequeño poblado de la región de Cataluña (España). A los dos años de edad falleció su madre y, tiempo después, también su padre. Por esa razón, quedó a cargo de un hermano mayor quien lo introdujo desde niño en el oficio de barbero al tiempo que lo asistía para que pudiera finalizar los estudios primarios en un pueblo cercano. En 1847, se trasladó a Barcelona donde permaneció diez años combinando su trabajo como barbero con sus estudios superiores. Inicialmente, se introdujo en la Escuela Industrial -creada en 1851 y actualmente en funcionamiento bajo el nombre de Escuela Técnica Superior de Ingeniería Industrial de Barcelona- para tomar cursos de francés, inglés, teneduría de libros y cálculo mercantil. Poco después ingresó a la Escuela Normal de Maestros de esa ciudad, creada en 1845, donde finalmente obtuvo el título de Maestro Normal de Instrucción primaria elemental. ${ }^{7}$

Durante sus años en Barcelona, participó de la agrupación masónica La Verdadera Iniciación y sufrió, junto a otros, la persecución política

\footnotetext{
6 Louis Guespin y Jean Baptiste Marcellesi, «Pour la glottopolitique», Langages, 83 (1986): 5-34.

7 Gabriel Carrasco, Apuntes biográficos contemporáneos: Provincia de Santa Fe (Rosario: Imprenta del Comercio, 1878).
} 
que lo llevaría al exilio. A finales de 1857 se embarcó rumbo a Buenos Aires acompañado por otros catalanes, entre quienes estaba Bartolomé Victory y Suárez, quien llevaría adelante una prolífica obra como editor, periodista e intelectual del socialismo en el Río de la Plata durante las décadas siguientes. ${ }^{8}$ Aliau, Victory y Suárez, y otros refundan, en marzo de 1858, La Verdadera Iniciación en Argentina. Posteriormente instalado en la ciudad de Rosario, Aliau seguiría participando de la masonería: se afilió en 1860 a la logia rosarina Unión $N .^{\circ} 17$, institución de la que fue presidente en 1862,1872 y $1873 .{ }^{9}$

Con residencia en Rosario, Aliau inició su labor pedagógica en una escuela de niñas y, en 1865, asumió como director del Liceo y Escuela de Artes y Oficios de esa ciudad. Desempeñó durante varios años una cátedra de Idioma Castellano en la Escuela Normal de la ciudad de Santa Fe y, trasladado nuevamente a Rosario, dictó una cátedra de Idioma Nacional en el Colegio Nacional de Rosario, a la que renunció en 1905, poco tiempo antes de fallecer. Ocupó el cargo de Inspector General de Escuelas de la provincia de Santa Fe entre 1876 y 1887. Fue autor de varias publicaciones orientadas a la enseñanza de la lengua española, entre las que se destacan una obra destinada a la alfabetización, Método razonado para enseñar a leer y escribir simultáneamente (1878), una publicación titulada Ejercicios del Lenguaje (1882), pensada para el estudio de la gramática, y Sobre la reforma de la ortografía actual (1882), un tratado en el cual se fundamenta la necesidad de reformar la ortografía del español y se describen las modificaciones propuestas.

\section{ALIAU FUNCIONARIO: ENTRE LA ENSEÑANZA DEL ESPAÑOL Y LA URGENCIA DE LA ESCOLARIZACIÓN}

Durante los años en que Aliau se desempeñó como funcionario de la cartera educativa del gobierno de Santa Fe (1876-1887), uno de los rasgos

\footnotetext{
8 Sobre la obra de Bartolomé Victory y Suárez, véase Horacio Tarcus, Los exiliados románticos. Socialistas y masones en la formación de la Argentina moderna (1853-1880) (Buenos Aires: Fondo de Cultura Económica, 2020); Horacio Tarcus, «La Biblioteca Popular de Bartolomé Victory y Suárez, primera editorial de la izquierda argentina: 1864-65», en Primer Coloquio Argentino de Estudios sobre el Libro y la Edición (La Plata, Argentina, 2012), 485-504.

9 Elena Rodríguez Lettieri, «El exilio español de la primera república y la masonería argentina», en La masonería española: represión y exilios, ed. José A. Ferrer Benimeli (Gobierno de Aragón: -Departamento de Educación, Cultura y Deporte, 2010), 117-135.
} 
sobresalientes de esa provincia tenía que ver con el componente demográfico. Las migraciones transatlánticas que tuvieron lugar a partir de mediados del siglo XIX cambiaron rápidamente la fisionomía de Santa Fe, una de las primeras provincias argentinas en recibir población migrante: entre 1856 y 1895 se formaron 350 colonias agrícolas, el número de habitantes de la provincia se cuadriplicó y, hacia el final de ese período, los extranjeros constituían el $42 \%$ de la población. ${ }^{10}$ Sin embargo, esa proporción se acentuaba en la región rural: un informe del año 1875 señala que alrededor del 70\% de los habitantes de las 32 colonias existentes en ese momento eran inmigrantes. ${ }^{11}$

En ese contexto, la organización de la escolaridad no era un tema menor: en los poblados se incrementaba el número de niños, los maestros escaseaban y la intervención política del gobierno provincial era rudimentaria. En 1872, cuando la campaña santafesina ya contaba con 31 colonias agrícolas, el Inspector Nacional de Colonias Guillermo Wilcken describía un escenario bastante precario en materia educativa:

La educación primaria, especialmente en las Colonias de Santa Fe, se halla muy descuidada. Las 31 Colonias con una población de 13.655 habitantes, solo poseen 14 escuelas con 650 alumnos en ellas; lo que da menos de una escuela por cada Colonia [...]. En la Colonia de San Carlos, por ejemplo, asisten a las dos escuelas solo 80 niños, quedando 600 sin enseñanza alguna. Este estado no puede ser más deplorable. ${ }^{12}$

En algunos pocos casos, el gobierno provincial enviaba dinero para costear mínimos gastos, pero en la mayoría de las localidades eran los propios pobladores quienes, de manera inorgánica o mediante sus precarias municipalidades, llevaban adelante la tarea de escolarizar a los

\footnotetext{
10 Ezequiel Gallo, Colonos en armas (Buenos Aires: Siglo XXI, 2007).

11 El informe elaborado por el Inspector de Colonias Guillermo Coelho indica que, de los 15.510 habitantes censados en las 32 colonias agrícolas de la provincia, 4.869 eran argentinos (31\%) y $10.641(69 \%)$ eran extranjeros, distribuidos en las siguientes nacionalidades, ordenadas demográficamente de mayor a menor: italianos, suizos, franceses, alemanes, ingleses, españoles, belgas, norteamericanos, otras naciones de América, otras naciones de Europa. Guillermo Coelho, Memoria presentada al Excmo. Gobierno de la Provincia de Santa Fe por el señor Inspector de Colonias (Buenos Aires: Imprenta de la Unión Argentina, 1875).

12 Guillermo Wilcken, Las colonias. Informe sobre el estado actual de las colonias agrícolas de la República Argentina (Buenos Aires: Sociedad Anónima, 1872), 3.
} 
niños. En algunos casos, contaban con maestros particulares y, en otros, eran los sacerdotes que se ocupaban de la atención religiosa quienes al mismo tiempo daban algunos rudimentos de educación elemental, en los espacios más óptimos que lograran conseguir. En 1875, el Inspector de Colonias Guillermo Coelho visitó la localidad de San Jerónimo y se lamentaba de que «tiene una capilla que sirve también para escuela pero que no llena las necesidades de la colonia para ninguno de los dos objetos». ${ }^{13}$ Lo mismo había advertido ya en 1872 Wilcken, señalando que «no hay edificio propio para escuela; falta que obliga al preceptor o maestro a enseñar en la capilla, que, como casi siempre está ocupada de funciones religiosas, esto ocasiona constantes interrupciones y por consiguiente mucho mal a la educación de los niños». ${ }^{14}$ Podría observarse una constante durante el período, y es justamente la inestabilidad: las escuelas, por las circunstancias mismas de la precariedad en la que se encontraban, tenían una corta vida, y los maestros eran fluctuantes ya que raramente eran profesionales de la educación y, además, debían lidiar con salarios penosos y atrasados.

En ese contexto, en 1876, Aliau asume el cargo de Inspector General de Escuelas de la provincia de Santa Fe, creado un año antes. La elaboración y difusión de su Método es un hito que podría ubicarse a caballo entre las dos facetas que caracterizaron a Aliau: la de pedagogo y la de funcionario público. Por un lado, su pericia profesional le ofrecía las herramientas necesarias para la elaboración de un método de alfabetización y, por otro, su cargo como inspector de escuelas le permitía conocer de primera mano las necesidades educativas de la provincia y lo investía de legitimidad para hacer implementar sus propuestas de enseñanza.

Hacia 1877, en una de sus primeras recorridas como funcionario público, el autor había advertido cuáles eran las principales dificultades en la campaña santafesina: el estado rudimentario, en términos materiales, en que se encontraba la escolarización y la presencia de personas sin formación pedagógica (y, en gran medida, no hispanohablantes) desempeñando funciones educativas. En un informe elevado en 1877 al

\footnotetext{
13 Coelho, Memoria, 27-28.

14 Wilcken, Las colonias, 32.
} 
Ministro de Instrucción Pública de Santa Fe, Manuel Pizarro, Aliau observaba:

En casi todas las escuelas faltan los útiles necesarios: cuadernos, lapiceras, plumas, tintas, tiza, pizarras, así como libros de lectura y pizarras murales de que carecen todas las escuelas de campaña. Sin estos útiles y especialmente sin la pizarra mural no puede haber progreso en la enseñanza por más inteligente que sea el maestro. [...] En el cuadro N. 7 están clasificados los maestros por nacionalidades resultado 29 argentinos, 16 españoles y 29 de otras naciones, siendo muy pocos los que tienen el título correspondiente que acredite su competencia. En esto puede observarse la necesidad de una escuela normal para formar maestros Argentinos, y para que el profesorado sea escogido, apto en la ciencia pedagógica, interesado en bien de la patria, y competente para la enseñanza de nuestro bello idioma. ${ }^{15}$

Entre las principales preocupaciones de Aliau estaba la de formar maestros argentinos que pudieran, entre otras cosas, enseñar el español. Sin embargo, ante la escasez de recursos materiales y humanos, el Método razonado para enseñar a leer y escribir simultáneamente contribuiría a resolver parcialmente algunas dificultades. Luego de publicada la obra, Aliau se dedicó a recorrer la provincia dictando conferencias pedagógicas a los docentes que se desempeñaran en las escuelas primarias, y distribuyendo el material para que sea usado en la alfabetización de los niños. Estas conferencias tuvieron una singular preponderancia en el espacio de las colonias agrícolas, ámbito en el cual se conjugaban dos de las carencias centrales: los pocos maestros existentes no tenían formación específica y la gran mayoría no enseñaba en español. ${ }^{16}$

Con todo, su lugar como funcionario público implicaba naturalmente la evaluación de prioridades y la consecuente toma de decisiones políticas. En abril de 1879, un grupo de vecinos de la colonia Esperanza le hizo llegar una solicitud para que gestionara el nombramiento de un maestro. La «sección oeste» de la colonia, habitada fundamentalmente

\footnotetext{
15 Archivo General de la Provincia de Santa Fe (en adelante AGPSF), Tomo 47, F. 430.

16 «Conferencia», El Colono del Oeste (Esperanza), 15 de marzo de 1879; «Solicitadas», El Colono del Oeste (Esperanza), 10 de mayo de 1879; «D. Isidro Aliau», El Colono del Oeste (Esperanza), 14 de junio de 1879.
} 
por familias de origen alemán, pedía al inspector que otorgara el cargo estable de maestro al profesor Emilio Hunziker, quien ya venía cumpliendo de facto esa tarea. Ante esa solicitud, Aliau deriva el pedido al Ministro de Gobierno añadiendo sus recomendaciones:

Sobre la solicitud adjunta, esta Inspección tiene el honor de informar a V.E. que D. Emilio Hunziker conoce poco el idioma nacional; pero atendiendo a que la mayor parte de los niños de la sección Oeste de Esperanza son alemanes, lo mismo que el Sr. Hunziker y que apenas se les entiende, podrían tal vez aprender algo con un preceptor de la misma nacionalidad. Así pues esta Inspección opina que V.E. acuerde como se pide en dicha solicitud, tanto más cuanto que la expresada escuela está sin funcionar hace mucho tiempo por falta de maestro. ${ }^{17}$

Esta comunicación permite advertir al menos una primera cuestión. La enseñanza de "nuestro bello idioma» es, para Aliau, un escenario deseable, un objetivo pedagógico, que no necesariamente supone la censura de otras lenguas. El valor primordial, en un contexto marcado por la escasez de recursos materiales y humanos, es la escolaridad en sí misma («podrían tal vez aprender algo») al margen de la lengua que se utilice para la enseñanza. En esta escena se advierte la confluencia de la faceta del pedagogo intelectual moviéndose dentro de los márgenes disponibles del funcionario público, en un contexto que no siempre resultaba favorable.

\section{EL MÉTODO DE ISIDRO ALIAU: SU CONTEXTO DE PUBLICACIÓN}

En 1877, siendo Inspector General de Escuelas y, de acuerdo con la ley vigente, el responsable de prescribir reglamentos y métodos, como así también de solicitar al gobierno la adopción de textos de enseñanza, Isidro Aliau escribió el Método razonado para enseñar a leer y escribir simultáneamente..$^{18}$ El 31 de diciembre de ese año, el gobierno provincial

\footnotetext{
17 AGPSF, Tomo 54, F. 454.

18 La ley provincial de educación de 1876, en su artículo 4. ${ }^{\circ}$, señala que son deberes del Inspector General de Escuelas «Dictar reglamentos y métodos de enseñanza para las escuelas, presentándolos a la aprobación del gobierno» (inc. 9) y «Solicitar de este la adopción de textos que han de servir para la enseñanza» (inc. 10). Registro Oficial de la Provincia de Santa Fe (ROPSF), Tomo IX, p. 221.
} 
publicó un decreto a través del cual ordenó la impresión de tres mil ejemplares de la obra, de los cuales la mitad se le entregarían al autor y la otra mitad quedarían a disposición del gobierno para ser distribuidos en las escuelas de la provincia. ${ }^{19}$

Previamente, la obra había sido sometida a evaluación a través de una comisión examinadora creada por el gobierno provincial a ese efecto, formada por el Inspector de Colonias Jonás Larguía, el profesor Antonio Pizzorno ${ }^{20}$ y el sacerdote Severo Echagüe. ${ }^{21}$ El dictamen fue favorable, aunque la comisión realizó algunas observaciones:

El expresado método ofrece grandes ventajas para instruir a la juventud, por cuanto a un mismo tiempo puede ella aprender la lectura de un método fácil y en muy corto tiempo. Sólo observamos que el método de lectura carece de algunas anotaciones que hagan más fácil su comprensión y que el autor ha prometido agregar, así que pueda darlo a la prensa mediante la protección de V.E. a que lo creemos acreedor.22

La preocupación por el método, presente en la evaluación de la comisión examinadora, era un asunto de época. Hasta mediados del siglo XIX, y en términos generales, la enseñanza de la lectura en Occidente se había llevado adelante siguiendo métodos muy elementales, con escaso nivel de comprensión por parte de los aprendices, que consistían, en la

19 ROPSF, Tomo IX, p. 457-458.

20 Antonio Pizzorno, oriundo de Italia, llegó a Argentina con el grado de maestro obtenido en su país natal. Desempeñó la cátedra de Gramática en los Colegios del Salvador (Buenos Aires) y en el de la lnmaculada Concepción (Santa Fe). Hacia 1873 pidió y obtuvo autorización para establecer una escuela particular que denominó «San Luis Gonzaga», la que funcionó 4 años. Al cabo de ese período fue designado director de una escuela comunal de Santa Fe. Leo Hillar Puxedou, Reseña histórica de la educación privada en la provincia de Santa Fe (Santa Fe: Ministerio de Educación de la Provincia de Santa Fe, 1989).

${ }_{21}$ Severo Echagüe, el primero en haber ocupado el cargo de Inspector General de Escuelas creado en 1875, había realizado estudios de filosofía y teología en Buenos Aires y Montevideo, para posteriormente regresar a la ciudad de Santa $\mathrm{Fe}$, ya como sacerdote, hacia fines de la década de 1850 . A partir de 1870, sin retirarse de sus funciones religiosas, ocupó distintos cargos ligados a la educación. En 1873, como Director de Enseñanza de la ciudad de Santa Fe, redactó el primer reglamento de escuelas municipales. La participación de la iglesia católica local en el ámbito de la educación, en general, y de la selección y evaluación de libros de enseñanza en particular, sería una constante al menos hasta finales del siglo XIX. Sergio Reinares, Santa Fe de la Vera Cruz: reseña histórica de la educación y sus escuelas desde su fundación hasta nuestros días (Santa Fe: Colmegna, 1946).

22 Reinares, Santa Fe, 234. 
mayoría de los casos, en el aprendizaje memorístico de un cierto número de oraciones religiosas. Habían sido los procesos desatados por la Reforma protestante y la Contrarreforma católica lo que produjo un interés por parte de las iglesias en cultivar en sus fieles el aprendizaje de la lectura. ${ }^{23}$ En el espacio colonial americano, si la lectura estaba reservada para un grupo selecto de la aristocracia blanca, eran aún menos quienes además aprendían a escribir. La escritura implicaba mayor tiempo de dedicación individual con cada aprendiz y requería una serie de instrumentos e insumos caros y de difícil acceso. Aprender a leer, en cambio, consistía en la memorización del abecedario que todos los alumnos podían corear de manera simultánea sin necesidad de demasiados enseres, más allá de algunas cartillas o silabarios, usualmente de bajo costo. Luego de eso, se avanzaba un poco más combinando algunas vocales y consonantes para memorizar sílabas. ${ }^{24}$

Sin embargo, luego de la caída de las monarquías y con el surgimiento de las nuevas repúblicas americanas, la educación del pueblo pasó a ocupar un lugar destacado entre los intereses de los incipientes Estados. La necesidad política de extender la alfabetización de manera rápida y efectiva, sumada a la progresiva conformación de un nuevo campo del saber orientado a reflexionar sobre las prácticas pedagógicas, dieron lugar a una serie de discusiones acerca de cuál era «el mejor» método de enseñanza. A esto se agrega una creciente preocupación no solo por proponer un método cada vez más eficaz respecto de los existentes, sino también por construir, por parte de los autores de las múltiples propuestas, un ethos pedagógico, que al tiempo que sirviera de respaldo para su método, los posicionara favorablemente en la discusión pública.

Para la época en que se publica el Método de Aliau, en las escuelas de la provincia de Santa Fe circulaban (probablemente entre otras obras) Anagnosia de Marcos Sastre y el Método de lectura gradual de Domingo

23 Inés Dussel y Marcelo Caruso, La invención del aula. Una genealogía de las formas de enseñar (Buenos Aires: Santillana, 1999); Anne-Marie Chartier, Enseñar a leer y escribir. Una aproximación histórica (México: Fondo de Cultura Económica, 2004).

24 Cucuzza y Pineau, Para una historia; Berta Braslavsky, «Para una historia de la pedagogía de la lectura en la Argentina ¿Cómo se enseñó a leer desde 1810 hasta 1930?», en Para una historia, eds. Cucuzza y Pineau, 2018: 35-49; Rodrigo Mayorga, «Un nuevo camino de la A a la Z: enseñanza y aprendizaje de la lectoescritura en la escuela primaria chilena del siglo XIX», Revista de Pensamiento Educativo, 46-47 (2010): 265-284. 
F. Sarmiento. ${ }^{25}$ Las obras de Sastre y de Sarmiento fueron publicadas casi al mismo tiempo y podrían ubicarse, metodológicamente, dentro de un mismo conjunto de materiales. Se trataba de propuestas que, si bien no se alejaban del todo del método memorístico utilizado en la etapa colonial, introducían la enseñanza de las letras según su fonética.

Anagnosia fue publicado por primera vez en Buenos Aires en el año 1849. En términos pedagógicos, se propone, a partir de tres máximas negativas, discutir los métodos utilizados hasta el momento: «no empezar con el abecedario», "no deletrear ni nombrar las consonantes», "no pasar de una lección mientras no esté bien sabida». En ese sentido, lo innovador consiste en no empezar con el aprendizaje del abecedario (como solía hacerse hasta ese momento a través de las cartillas y silabarios) sino introducir sucesivamente las letras según las dificultades que el autor suponía que tenían en su relación con los sonidos.

Por su parte, el Método de lectura gradual de Sarmiento fue publicado por primera vez en 1845 en Chile, e inmediatamente adoptado para la enseñanza en los establecimientos públicos de ese país. ${ }^{26}$ No hay precisiones en cuanto al momento en que la obra ingresó a la Argentina, aunque se sabe que la primera edición local es del año 1870 a cargo de la editorial Coni. ${ }^{27} \mathrm{Al}$ igual que Anagnosia, la obra de Sarmiento también se presentaba, a partir de enunciados negativos, como una superación de los métodos que venían utilizándose hasta el momento: «no se enseñará eme, sino me». Si bien el método seguido por Sastre y Sarmiento constituyó un cambio respecto a las cartillas y silabarios usados durante la colonia, una de las principales limitaciones que suelen señalarse es que mantiene la base memorística de los antiguos métodos. ${ }^{28}$

\footnotetext{
25 Wilcken, Las colonias, 10; y «A los maestros», El Colono del Oeste (Esperanza), 5 de junio de 1880.

26 Mayorga, «Un nuevo camino».

27 Carlos Stuardo Ortiz, El método de lectura gradual de Domingo F. Sarmiento. Datos para su historia y bibliografía (Santiago de Chile: Imprenta Universitaria, 1949).

28 Sin embargo, es necesario advertir que el público destinatario de estos aprendizajes provenía, fundamentalmente, de comunidades en las cuales la oralidad y la memoria jugaban un papel preponderante. Desde ese escenario, Mayorga (2010) observa que, en la propuesta sarmientina, el papel ocupado por la memoria era de vital importancia, pero su utilización metodológica tenía como fin configurar una pedagogía que la erradicara definitivamente del proceso de enseñanza de la lectura. La mnemotecnia solo cobraba sentido subordinándose al servicio de la inducción: la irrupción de la palabra escrita en las mentes predominantemente orales de los niños se operacionalizaba apoyada directamente por la misma capacidad que se buscaba neutralizar dentro del proceso lector. Para un
} 


\section{UN MÉTODO PARA ALFABETIZAR EN UN ESPACIO PRECARIO Y DIVERSO}

La obra de Isidro Aliau, publicada algunas décadas más tarde que Anagnosia y que el Método de lectura gradual, se ubica entre los métodos que se instalaron con fuerza hacia 1880 , que proponían dos innovaciones centrales: la enseñanza simultánea de la lectura y la escritura, y la utilización de una palabra o frase como unidad de sentido inicial que luego se descompone en unidades menores (sílabas y letras). Tal como en Sastre y Sarmiento, en Aliau pueden identificarse las huellas que lo inscriben dentro de la "polémica por el método». El título completo de la obra es: «Método razonado para enseñar a leer y escribir simultáneamente con más facilidad y perfección que por otros métodos» y en el prólogo se aclara que «el discípulo aprende a leer con facilidad y perfección sin que se sacrifique la ortografía o el buen sentido como sucede en casi todos los métodos conocidos». ${ }^{29}$

Además, otro rasgo notable de la obra es que fue producida por un maestro diplomado, lo cual no constituía un dato menor en la Argentina de la época: las escuelas normales eran aún incipientes, ${ }^{30}$ con lo cual los docentes que contaran con título habilitante eran escasos, y los métodos que se empleaban en ese momento no habían sido concebidos por profesionales con titulación específica en la materia. En ese sentido, buscando reforzar la construcción de un ethos de pedagogo competente, la portada del libro señala a continuación del nombre del autor: «Isidro Aliau. Profesor de Instrucción Primaria Superior, graduado en la Escuela Normal de Barcelona e Inspector General de Escuelas de la Provincia de Santa Fe». El autor se presenta con sus credenciales pedagógicas, pero también con las de funcionario público, lo que contribuye a reforzar su legitimidad.

En el prólogo del Método pueden verse las huellas del propósito pragmático de la obra (alfabetizar rápidamente en español) contando con un

\footnotetext{
análisis más detallado de los métodos de Sarmiento y Sastre, pueden verse Braslavsky (2018), Cucuzza (2018), Arnoux (2013) y Mayorga (2010).

29 Isidro Aliau, Método razonado para enseñar a leer y escribir (Buenos Aires: Imprenta Europea, 1884), 4. En adelante, todos los destacados en las citas me pertenecen.

30 Hacia 1875 solo había cuatro escuelas normales en el país: una en Paraná (1871), una en San Miguel de Tucumán (1875) y dos en la ciudad de Buenos Aires (1874).
} 
plantel de maestros deficiente cuantitativa y cualitativamente: «Este método, fundado en la práctica y en la observación del de Jacotot, pone al discípulo en aptitud de aprender por sí solo toda clase de sílabas sin necesidad de que el maestro las pronuncie antes».31 Joseph Jacotot, en quien dice apoyarse Aliau, fue un pedagogo francés nacido en Dijon en 1770. Con la restauración monárquica producida luego de la Revolución Francesa, Jacotot -ya siendo profesor de Literatura clásica-, se exilió en Bélgica y continuó trabajando en la universidad de Lovaina. Allí se enfrentó a la dificultad de trabajar con estudiantes que solo hablaban flamenco (lengua que él no dominaba) y desconocían el francés. En esas circunstancias, resolvió utilizar una edición bilingüe del Télémaque de Fenelón. Mediante un intérprete, encargó a los alumnos que aprendieran de memoria el texto francés y lo fueran comprendiendo mediante la traducción. En el tiempo de unas pocas semanas, comprendían la ortografía y escribían el francés con fluidez y sin dificultades. Esa experiencia lo motivó a reflexionar en torno a la capacidad de aprender de los discípulos, incluso a costa de un «maestro ignorante».32

En términos metodológicos, la técnica empleada por Jacotot consistía en tres partes: mnemónica, analítica y sintética. En la primera se confía a la memoria el texto partiendo de una sentencia («Calypso ne pouvait se consoler du départ d'Ulysse», en el caso del Télémaque), en la segunda se obliga al discípulo a reflexionar y distinguir él mismo las voces y las relaciones que unen las ideas, y en la tercera se hace componer redacciones al alumno sobre distintos temas con los materiales que ha encontrado en las dos primeras. ${ }^{33}$ En el mismo sentido, Aliau inicia sus lecciones a partir de la cláusula «Mañana beberé agua de perifollo y comeré chuleta sazonada». ${ }^{34}$ Esta frase debe ser memorizada para posteriormente avanzar sobre la identificación de la cantidad de palabras,

\footnotetext{
31 Aliau, Método, 4.

32 Acerca de las ideas pedagógicas de Joseph Jacotot, más allá de su experiencia en enseñanza de la lengua francesa, véanse Inés Dussel, «Jacotot o el desafío de una escuela de iguales». Educação \& Sociedade, 24-82 (2003): 213-219 y Xavier Laudo Castillo, «Educación y emancipación: de la experiencia de Jacotot a la expectativa de Rancière», Educació i Història: Revista d'Història de l'Educació, 21 (2013): 65-87.

33 Xavier Laudo Castillo, «Educación y emancipación».

34 Esta misma clave será utilizada también en su obra Ejercicios del Lenguaje (1882) y en Sobre la reforma de la ortografía actual (1882), en esta última como sentencia disparadora para la enseñanza de los sonidos de las letras.
} 
su orden y la entonación que debe darse a la frase. Finalmente, se pasa a la descomposición en sílabas y letras que se recombinarán con otras y formarán nuevas palabras. En última instancia, solo cuando los alumnos sepan leer, se enseñará el abecedario.

El método de Aliau otorga un espacio preponderante a la entonación en la lectura «en vista de los defectos de articulación y pronunciación que se notan en los niños que salen de las escuelas». ${ }^{35}$ Considerando, como se ha señalado, el problema de la falta de maestros capacitados o bien desconocedores del español y sus dicciones, en el prólogo de su obra dedica un extenso párrafo con advertencias a los maestros, acerca de cuándo y cómo deben hacerse las inflexiones de la voz frente a los diferentes signos de puntuación (interrogativos, exclamativos, paréntesis, etc.), «suponiendo que algunos maestros ignoren las cadencias que deben hacerse en las pausas». ${ }^{36}$

En suma, el Método de Aliau puede ser leído en dos planos. Por un lado, en tanto instrumento lingüístico-pedagógico "hijo de su tiempo» que recoge las discusiones en boga en el campo educativo -el método más adecuado para alfabetizar- y la problemática demográfica de la provincia, esto es, la acelerada multiplicación de colonias con niños no hispanoparlantes y maestros escasamente calificados, situación que requería un marco de organización en términos educativos. Pero, por otro lado, el Método es también un lugar de enunciación para Aliau: una discursividad que le permite presentar sus credenciales profesionales y políticas, al tiempo que lo introduce en el debate público.

\section{«ÁBRASE PUES, EL TEMPLO A TODOS»: LA PROPUESTA DE REFORMA ORTOGRÁFICA}

En 1882, con motivo de celebrarse el Primer Congreso Pedagógico en la ciudad de Buenos Aires, Isidro Aliau y Estanislao Zeballos fueron designados por el gobierno de Santa Fe como delegados provinciales. Como se sabe, el Congreso tenía como propósito central reunir a intelectuales, pedagogos y maestros, junto a representantes de las distintas provincias del país e incluso referentes extranjeros, para debatir las

\footnotetext{
35 Aliau, Método, 4.

36 Aliau, Método, 4.
} 
problemáticas centrales en materia educativa, y elaborar conclusiones que sirvieran como base para la sanción de una ley nacional de educación. Aliau propuso disertar sobre tres puntos: a) la necesidad de una reforma ortográfica; b) la cultura social en la escuela primaria; y c) los procedimientos más eficaces para enseñar a viva voz y sin texto algunos ramos elementales. Luego de preparadas las correspondientes disertaciones, la comisión organizadora del Congreso solo le permitió disertar sobre el segundo punto. Sin embargo, su propuesta de reforma ortográfica fue explicada y presentada a través de una publicación editada ese mismo año, Sobre la reforma de la ortografía actual, que el autor hizo llegar al gobierno de Santa Fe junto al informe anual de 1882 acerca del estado de la educación en la provincia.

En su escrito, Aliau reconoce que no está solo ni parte de cero al presentar su propuesta de reforma ortográfica. Otros antes que él han hecho intentos, algunos fructuosos, por introducir cambios en la grafía de la lengua española, basados en la necesidad de utilizar la pronunciación como regla para establecer la ortografía. En ese sentido, recoge e introduce los nombres de «notabilísimos gramáticos»: Antonio de Nebrija, Antonio Martínez de Noboa, Mariano de Rementería y Fica, Andrés Bello, [?] Flores y Juan de Becerril. Párrafo aparte dedica a Domingo Faustino Sarmiento quien, junto a Andrés Bello, había impulsado una reforma ortográfica en Chile durante la década de 1840:

Sarmiento la ha iniciado entre nosotros, pero incompleta y sin decir el modo de enseñar el abecedario en las escuelas [...]. Los citados gramáticos disienten en el modo de realizar la reforma: unos suprimen letras que en mi concepto no deben suprimirse; otros aumentan signos inútiles, y ninguno ha hecho un estudio detallado del abecedario para presentarlo al aprendizaje de los niños, de un modo tan fácil como yo lo presento. ${ }^{37}$

En primer lugar, a Sarmiento le reconoce el antecedente de intento reformista, al tiempo que desliza una crítica al carácter «incompleto» de su obra, en la medida en que no habría estado pensada para trasladar esa reforma a la enseñanza escolar. Esta operación pone de manifiesto el

\footnotetext{
37 Isidro Aliau, Sobre la reforma de la ortografía actual para escribir el idioma tal cual se habla (Buenos
} Aires: Establecimiento Tipográfico, 1882), 7. 
carácter fuertemente polémico del discurso de Aliau, que había sido proyectado para pronunciarse en el marco del Congreso Pedagógico. Sarmiento, que si bien no asistió a pesar de haber sido nombrado presidente honorario del evento, siguió muy de cerca los debates, y participó a través de críticas desde la prensa. La atención de Sarmiento a todo lo que allí se discutía hubiera garantizado repercusión en torno a la propuesta de Aliau pero, como se ha señalado, la comisión organizadora desestimó esa intervención.

En segundo lugar, la cita precedente arroja una crítica generalizada a los proyectos ya conocidos sobre reformas ortográficas: por un lado, señala que esas propuestas postulan ciertos cambios con los que Aliau disiente y, por otro lado, al igual que Sarmiento, no habrían pensado en una óptima articulación con la enseñanza. La propuesta de Aliau se ofrece, así, como el modo más fácil de llevar a las aulas los cambios introducidos en la ortografía de la lengua española, operación que lo posiciona en un doble rol: el de especialista competente, que evalúa alternativas y define la más adecuada, y el de maestro experimentado que conoce y es capaz de diseñar el mejor método para que esos cambios sean aprendidos fácilmente.

En términos generales, su propuesta propone modificar la ortografía del español utilizando como única regla la pronunciación. Las modificaciones contempladas podrían sintetizarse del siguiente modo:

- Suprimir la $c$ (que sería reemplazada por la $k$ en $c a, c o, c u$, y por la $z$ en los casos ce y ci).

- Reemplazar la ch por la $h$.

- Suprimir la $u$ y la $h$ mudas.

- Cambiar $g$ por $j$ antes de $e-i$, quedando el uso de la $g$ solo en articulación gutural suave.

- Suprimir la $q$ (que sería reemplazada por la $k$ ).

- Utilizar siempre $r r$ cuando se indique sonido fuerte, incluso al inicio de la palabra.

- Suprimir la $x$, permaneciendo solo como letra numeral. 
- La y se usará solo en articulación con vocales.

- Reemplazar $v$ por $b$, salvo en nombres propios o en palabras equívocas.

En suma, luego de suprimidas las letras que considera «inútiles»o «escedentes» ( $\mathrm{sic}$ ), el nuevo alfabeto de Aliau se compone de veinte consonantes y cinco vocales: «Con estas letras se escribirá el idioma tal cual se habla tomando por base la precisa y esclusiva pronunciación de cada letra». .38

Para sostener su propuesta, parte de una premisa que busca postular el carácter «natural» de utilizar la pronunciación como base para la grafía de una lengua:

La escritura alfabética es la representación, por medio de signos convencionales, de la palabra hablada; y como para ésta hay articulaciones y sonidos que no pueden confundirse, parece natural que para la escritura no haya más regla que la pronunciación. ${ }^{39}$

Con ese punto de partida, va a cuestionar las otras dos grandes reglas que rigen la ortografía de la lengua española: el uso y la etimología. En primer lugar, el argumento central para desestimar esos dos criterios en favor de la base fonológica es su carácter elitista: si el idioma se escribe «tal cual se habla» su escritura se aprende de manera mucho más rápida y está al alcance de todos, incluso de aquellos que están obligados a abandonar tempranamente la escolarización. Si, en cambio, se siguen las reglas del uso, «muchas veces caprichoso, y la etimología, no se consigue escribir con ortografía sino con mucha práctica y mucho estudio». ${ }^{40}$ En segundo lugar, recurre a ejemplos para señalar una extensa lista de palabras cuya grafía fue transformada entre los siglos XIII y XVI, «atendiendo a la eufonía o buen sonido, y sin tener para nada en cuenta el uso»: mugieres, homes, quando, agora, ningunt, variedat, invidia, entre otras. ${ }^{41}$

\footnotetext{
38 Aliau, Sobre la reforma, 13.

39 Aliau, Sobre la reforma, 3.

40 Aliau, Sobre la reforma, 4.

41 Aliau, Sobre la reforma, 4.
} 
Para cuestionar el criterio etimológico recurre a Roque Barcia, lexicógrafo español autor y coautor de varias obras, entre las cuales se pueden mencionar: Nuevo diccionario de la lengua castellana (1853), Sinónimos castellanos (1863-1865), Formación de la lengua española derivada de la formación natural e historia del idioma moderno (1872), y el Primer diccionario general etimológico de la lengua española, compuesto de cinco tomos publicados entre 1880 y 1883 . Aliau recoge esa autoridad para fundamentar su crítica a «ciertas anomalías [etimológicas] consentidas por los académicos y censuradas por Barcia». Y a continuación enumera una larga serie de palabras que comparten raíz etimológica y, sin embargo, presentan diferentes grafías: «De fuego [deriva] hoguera ¿por qué no se dice foguera?", ¿Por qué caber y cabida se escriben con $b$ y cavidad, que es la cabida de todo cóncavo, se escribe con $v$ ?», etc. ${ }^{42}$

Ubicar a los académicos como los guardianes celosos de esos principios ortográficos es otro de los aspectos que contribuyen a reforzar el carácter polémico del tratado de Aliau. Las críticas a la Real Academia Española son recurrentes a lo largo de su discurso:

No pesando aquí como en España, esta autoridad conservadora, podemos ser revolucionarios de la ortografía, ya que su reforma es conveniente y fácil, como creo haber demostrado, y puede introducirse sin atacar las creencias y los sentimientos del pueblo. ${ }^{43}$

Este enunciado supone una doble operación. Por un lado, reclama la soberanía para tomar decisiones «revolucionarias» en materia ortográfica, apoyándose en el carácter de Estado independiente de la República Argentina. En cierta medida, el argumento se inscribe en una memoria construida por otros discursos reformistas. Tempranamente, la llamada Generación del 37 había abogado por una emancipación lingüística que debería sobrevenir a la emancipación política de 1816. Tiempo después, en Sarmiento se volvería a recuperar ese argumento a partir de la postulación de la pronunciación americana como criterio para establecer una nueva ortografía y en el rechazo a la legitimidad de la RAE para tutelar

\footnotetext{
42 Aliau, Sobre la reforma, 4.

43 Aliau, Sobre la reforma, 15.
} 
la lengua de las naciones americanas. ${ }^{44} \mathrm{Y}$, casi de manera contemporánea a la propuesta de Aliau, Juan María Gutiérrez rechazaba en 1875 el título de miembro correspondiente otorgado por la Real Academia Española, alegando (entre otras cosas) que los hablantes americanos no deben subordinarse a las normas peninsulares. ${ }^{45}$ En este sentido, Aliau apela a un argumento caro para ciertos sectores de las elites intelectuales sudamericanas, entre quienes estaba el propio Sarmiento que, como se dijo, era un participante clave del debate público en torno al Congreso Pedagógico.

Por otro lado, al señalar que la reforma, tal como está planteada, puede introducirse fácilmente sin «atacar las creencias y sentimientos del pueblo», Aliau vuelve a legitimar su lugar como intelectual del campo del lenguaje. Sabe (y quiere marcar que sabe) que la ortografía tiene una relación directa con la identidad de los hablantes y que cualquier modificación puede afectar a diversos niveles de la vida social: la identidad lingüística de la comunidad, su relación con las lenguas, la identificación de hablantes con su propia variedad escrita, etc. ${ }^{46}$ Asimismo, asegurando que la reforma no entrañará consecuencias negativas en relación con la identidad del pueblo trata de anticiparse a reacciones que, sabe, han tenido otros intentos reformistas. La propuesta de Sarmiento había sido en cierto punto cuestionada en Chile debido a su radicalidad, insistiendo sus críticos en la moderación que debe suponer

\footnotetext{
44 En 1843, durante los debates producidos en Chile a propósito de los intentos reformistas de Sarmiento y su polémica con Andrés Bello (reformista moderado), había escrito: «[E]l estarnos esperando que una academia impotente, sin autoridad en España mismo, sin prestigio y aletargada por la conciencia de su propia nulidad nos dé reglas, que no nos vendrán bien después de todo, es abyección indigna de naciones que han asumido el rango de tales» (citado por Barry Velleman, «Antiacademicismo lingüístico y comunidad hispánica: Sarmiento y Unamuno», en La batalla del idioma: la intelectualidad hispánica ante la lengua, eds. José Del Valle y Luis Gabriel-Stheeman (Madrid: Iberoamericana/Vervuert, 2004), 4.
}

45 Elvira Arnoux, «Marcar la nación en la lengua: la reforma ortográfica chilena (1843-1844)». Revista de Estudios de Ciencias Sociales y Humanidades, 16 (2006): 41-54; Ángela Di Tullio, Políticas lingüísticas e inmigración. El caso argentino (Buenos Aires: Eudeba, 2010); Juan Antonio Ennis, Decir la lengua: Debates ideológico-lingüísticos en Argentina desde 1837 (Frankfurt am Main: Peter Lang, 2008); Mara Glozman y Daniela Lauria, Voces y ecos. Una antología de los debates sobre la lengua nacional (Argentina. 1900-2000) (Buenos Aires: Cabiria. Ediciones de la Biblioteca Nacional, 2012).

46 Xoán Lagares, «Dinâmicas normativas e autoridade linguística em espanhol e em português: a gestão da ortografia», en Temas de política linguística no processo de integração regional, eds. Socorro Tavares de Sousa, María del Pilar Roca y Andrea Silva Ponte (Campinas: Pontes, 2018), 175-198. 
una reforma de esta naturaleza y en la necesidad de que los cambios sean fruto del consenso. ${ }^{47}$

Finalmente, es importante insistir sobre la impronta fuertemente polémica del discurso de Aliau, sobre todo en dos planos: por un lado, en el carácter marcadamente democratizante que atribuye a la escolaridad y, por otro, en la interpelación a las autoridades políticas como responsables de garantizar esa igualdad:

Ábrase pues, el templo a todos. Que no haya doctos y profanos. Póngase en manos del obrero de la materia un instrumento que pueda manejar con la misma facilidad que el literato y elevarse, por su propio esfuerzo, a la categoría de un publicista [...]. Enseñando de este modo el abecedario en las escuelas, nuestros descendientes no serán como nosotros, esclavos del uso y de la etimología, e introducirán la reforma sin dificultad si los hombres de Estado y los maestros de escuela la prohíjan [...]. La ortografía será patrimonio de todos y podremos decir: Obreros de la materia y de la inteligencia; sois iguales para manejar este imprescindible instrumento de publicidad [destacado en el original]. ${ }^{48}$

Reformar la ortografía como medio para facilitar el acceso rápido a la cultura escrita tampoco resulta un hallazgo de Aliau. Ya la propuesta de Sarmiento se apoyaba, en gran medida, en el carácter democratizante de una ortografía con criterio fonológico, en relación con la necesidad de extender la alfabetización de las masas. Sin embargo, el tono de prédica revolucionaria y provocadora, al cuestionar los propios privilegios («no serán como nosotros»), le otorga al argumento por la igualdad social un nuevo tono. No hay que olvidar, nuevamente, que se trata de un discurso que fue proyectado para pronunciarse en presencia de los intelectuales más reconocidos en materia educativa, educadores y funcionarios del Estado. La propuesta de reforma ortográfica de Aliau debe ser leída en esos dos planos: en tanto proyecto de intervención lingüística y como operación de confrontación polémica en un tiempo y en un espacio donde se sentaban las bases del sistema educativo nacional.

47 Elvira Arnoux, «Marcar la nación en la lengua: la reforma ortográfica chilena (1843-1844)», Revista de Estudios de Ciencias Sociales y Humanidades, 16 (2006): 41-54.

48 Aliau, Sobre la reforma, 4, 14. 


\section{REFLEXIONES FINALES}

La recuperación de la figura de Isidro Aliau y su obra permite reflexionar sobre la voluntad intervencionista que sobre el lenguaje han tenido diversos actores políticos e intelectuales en la Argentina del siglo XIX. Los orígenes del sistema educativo nacional, en diálogo con otros fenómenos sociales que se produjeron de manera contemporánea, como la inmigración masiva, aceleraron la proliferación de discursos, prácticas y normas tendientes a intervenir sobre ciertos aspectos del lenguaje, sobre todo en el campo educativo. Sin embargo, como se ha señalado, las intervenciones sobre la lengua suponen indefectiblemente una disputa por el poder, y es desde ese marco que deben comprenderse los márgenes de circulación de ciertos discursos. Para el caso de Aliau, la imposibilidad de introducir su proyecto de reforma ortográfica en la escena pública es un dato revelador de esas disputas, que exceden el ámbito de lo estrictamente lingüístico. Cabe preguntarse, en ese sentido, cuáles son los espacios de agencia efectivos de los que dispone un sujeto relativamente marginal de la escena política, en un contexto fuertemente centralista.

Por otra parte, el análisis presentado señala la relevancia de abordar estas intervenciones en una doble dimensión. En el caso de la obra de Aliau, su método de alfabetización y su tratado sobre la reforma ortográfica deben ser leídos en tanto discursos que se inscriben en un determinado lugar de enunciación: el del pedagogo experto en el campo del lenguaje que cuenta con preparación formal, experiencia y competencia para evaluar y proponer alternativas de enseñanza, al tiempo que es capaz de intervenir en el corpus de la lengua y modificar su ortografía. En tanto políticas del lenguaje, sus intervenciones deben ser analizadas atendiendo al posicionamiento político que subyace a su voluntad pedagógica y reformista: una concepción igualitaria y democratizante acerca de la lectura y la escritura. No debe perderse de vista, en este sentido, la impronta de su actividad política a la que hemos hecho referencia al desarrollar su trayectoria biográfica. El compromiso de Aliau con los principios igualitarios y emancipadores del socialismo, como así también con los preceptos de ilustración de las agrupaciones masónicas debe articularse con sus ideas acerca de la escolarización. Aliau ve en la alfabetización la llave para acceder a una sociedad de iguales y es desde ese lugar que va a construir su discursividad con una impronta fuertemente 
polémica, buscando hacerse un lugar en la discusión que sentará las bases del sistema educativo argentino.

\section{Nota sobre la autora}

MónICA BaRetTa es licenciada en Comunicación Social, Magíster en Análisis del Discurso y becaria doctoral del Consejo Nacional de Investigaciones Científicas y Técnicas (CONICET) para el Doctorado en Lingüística (Universidad de Buenos Aires). Es docente de la Escuela de Humanidades de la Universidad Nacional de San Martín. Participa en diversos proyectos de investigación radicados en el CELES (Centro de Estudios del Lenguaje en Sociedad - LICH - UNSAM). Su tema de investigación actual se orienta hacia el estudio de las políticas del lenguaje concernientes a la lectura y la escritura durante el siglo XIX, en el marco de la inmigración europea en Argentina.

\section{REFERENCIAS}

Aliau, Isidro. Método razonado para enseñar a leer y escribir. Buenos Aires: Imprenta Europea, 1884.

Aliau, Isidro. Informe de inspección de escuelas. s/d, 1882a.

Aliau, Isidro. Sobre la reforma de la ortografía actual para escribir el idioma tal cual se habla. Buenos Aires: Establecimiento Tipográfico, 1882b.

Arnoux, Elvira. «Las leyes de defensa de la lengua en la Argentina: propuestas y debates al finalizar los siglos XIX y XX». Letterature d'America, XXIV, 100 (2003): 23-50.

Arnoux, Elvira. «Marcar la nación en la lengua: la reforma ortográfica chilena (1843-1844)». Revista de Estudios de Ciencias Sociales y Humanidades, 16 (2006): 41-54.

Arnoux, Elvira. «La enseñanza de las primeras letras en la puesta en marcha de un sistema estatal moderno: el "Método de lectura gradual" (Valparaíso, 1845) de Domingo Faustino Sarmiento». En Penser l'histoire des savoirs linguistiques. Hommage à Sylvain Auroux, editado por Sylvie Archimbault, Jean-Marie Fournier y Valérie Raby, 437-452. Paris: ENS Éditions, 2013.

Arnoux, Elvira. «Glotopolítica: delimitación del campo y discusiones actuales con particular referencia a Sudamérica». En Lengua y política en América Latina: Perspectivas actuales. Actas del II Coloquio Internacional de Estudios Latinoamericanos de Olomouc (s/p). Olomouc: Univerzita Palackého v Olomouci, 2014. 
Braslavsky, Berta. «Para una historia de la pedagogía de la lectura en la Argentina ¿Cómo se enseñó a leer desde 1810 hasta 1930?». En Para una historia de la enseñanza de la lectura y escritura en Argentina. Del catecismo colonial a La Razón de Mi Vida, 35-49, editado por Héctor Cucuzza y Pablo Pineau. Buenos Aires: Miño y Dávila, 2018.

Carrasco, Gabriel. Apuntes biográficos contemporáneos: Provincia de Santa Fe. Rosario: Imprenta del Comercio, 1878.

Chartier, Anne-Marie. Enseñar a leer y escribir. Una aproximación histórica. México: Fondo de Cultura Económica, 2004.

Coelho, Guillermo. Memoria presentada al Excmo. Gobierno de la Provincia de Santa Fe por el señor Inspector de Colonias. Buenos Aires: Imprenta de la Unión Argentina, 1875.

Cucuzza, Héctor. «Leer y rezar en la Buenos Aires aldeana». En Para una historia de la enseñanza de la lectura y escritura en Argentina. Del catecismo colonial a La Razón de Mi Vida, editado por Héctor Cucuzza y Pablo Pineau, 51-74. Buenos Aires: Miño y Dávila, 2018.

Cucuzza, Héctor y Pablo Pineau (eds.). Para una historia de la enseñanza de la lectura y escritura en Argentina. Del catecismo colonial a La Razón de Mi Vida. Buenos Aires: Miño y Dávila, 2018.

Di Stefano, Mariana. El lector libertario. Prácticas e ideologías lectoras del anarquismo argentino (1898-1915). Buenos Aires: Eudeba, 2013.

Di Tullio, Ángela. Políticas lingüísticas e inmigración. El caso argentino. Buenos Aires: Eudeba, 2010.

Dussel, Inés. "Jacotot o el desafío de una escuela de iguales». Educação \& Sociedade, 24-82 (2003): 213-219.

Dussel, Inés y Marcelo Caruso. La invención del aula. Una genealogía de las formas de enseñar. Buenos Aires: Santillana, 1999.

Ennis, Juan Antonio. Decir la lengua: Debates ideológico-lingüísticos en Argentina desde 1837. Frankfurt am Main: Peter Lang, 2008.

Gallo, Ezequiel. Colonos en armas. Buenos Aires: Siglo XXI, 2007.

Glozman, Mara y Daniela Lauria. Voces y ecos. Una antología de los debates sobre la lengua nacional (Argentina. 1900-2000). Buenos Aires: Cabiria. Ediciones de la Biblioteca Nacional, 2012.

Guespin, Louis y Jean Baptiste Marcellesi. «Pour la glottopolitique». Langages, 83 1986): 5-34.

Hillar Puxedou, Leo. Reseña histórica de la educación privada en la provincia de Santa Fe. Santa Fe: Ministerio de Educación de la Provincia de Santa Fe, 1989.

Lagares, Xoán. «Dinâmicas normativas e autoridade linguística em espanhol e em português: a gestão da ortografia». En Temas de política linguística no processo de integração regional, editado por Socorro Tavares de Sousa, María del Pilar Roca y Andrea Silva Ponte, 175-198. Campinas: Pontes, 2018. 
Laudo Castillo, Xavier. «Educación y emancipación: de la experiencia de Jacotot a la expectativa de Rancière». Educació i Història: Revista d'Història de l'Educació, 21 (2013): 65-87.

Lauria, Daniela. «Los diccionarios argentinos de "barbarismos": análisis glotopolítico de los publicados entre 1890 y 1903». Káñina, XLIII, 3 (2019): 3966.

Mayorga, Rodrigo. «Un nuevo camino de la A a la Z: enseñanza y aprendizaje de la lectoescritura en la escuela primaria chilena del siglo XIX». Revista de Pensamiento Educativo, 46-47 (2010): 265-284.

Reinares, Sergio. Santa Fe de la Vera Cruz: reseña histórica de la educación y sus escuelas desde su fundación hasta nuestros días. Santa Fe: Colmegna, 1946.

Rodríguez Lettieri, Elena. «El exilio español de la primera república y la masonería argentina». En La masonería española: represión y exilios, editado por José A. Ferrer Benimeli, 175-135. Gobierno de Aragón: Departamento de Educación, Cultura y Deporte, 2010.

Stuardo Ortiz, Carlos. El método de lectura gradual de Domingo F. Sarmiento. Datos para su historia y bibliografía. Santiago de Chile: Imprenta Universitaria, 1949.

Tarcus, Horacio. Los exiliados románticos. Socialistas y masones en la formación de la Argentina moderna (1853-1880). Buenos Aires: Fondo de Cultura Económica, 2020.

Tarcus, Horacio. «La Biblioteca Popular de Bartolomé Victory y Suárez, primera editorial de la izquierda argentina: 1864-65». En Primer Coloquio Argentino de Estudios sobre el Libro y la Edición, 485-504, La Plata: Argentina, 2012. Instituto de Investigaciones en Humanidades y Ciencias Sociales, UNLP.

Velleman, Barry. «Antiacademcismo lingüístico y comunidad hispánica: Sarmiento y Unamuno». En La batalla del idioma: la intelectualidad hispánica ante la lengua, editado por José Del Valle y Luis Gabriel-Stheeman, 35-66. Madrid: Iberoamericana/Vervuert, 2004.

Wilcken, Guillermo. Las colonias. Informe sobre el estado actual de las colonias agrícolas de la República Argentina. Buenos Aires: Sociedad Anónima, 1872. 